\title{
The acute consumption of cocoa derived flavanols results in improvements in executive function and a reduction in blood pressure in a healthy older adult population
}

\author{
C. J. Saunders ${ }^{1,2}$, L. T. Butler ${ }^{2}$, J. A. Ellis ${ }^{2}$, C. Williams ${ }^{2}$, R. Adkins ${ }^{2}$, R. Kean ${ }^{2}$ and J. P. E. Spencer ${ }^{1}$ \\ ${ }^{1}$ School of Food and Nutritional Sciences, University of Reading, Reading, RG6 6AH, UK and ${ }^{2}$ School of Psychology \\ and Clinical Language Sciences, University of Reading, Reading, RG6 6AH, UK
}

Epidemiology suggests that individuals who consume a diet rich in flavonoid containing foods have a reduced risk of neurodegenerative disease $^{(1)}$. These observations are of particular interest to public health due to the increasing prevalence of dementia and the absence of effective therapies. It is well established that flavanols, found in cocoa are able to improve cerebral blood flow ${ }^{(2)}$ and reduce risk factors common to both CVD and dementia ${ }^{(3)}$. More specifically, dietary intervention studies have shown that flavonoid rich blueberries and cocoa can improve cognitive function ${ }^{(4)}$. The aim of this study was to investigate the acute effects of a high flavanol (HF) cocoa drink $(600 \mathrm{mg})$ compared with a, macro and micronutrient matched, low flavanol (LF) cocoa drink (23 mg) on cognitive function and blood pressure in sixty-three healthy older adults (aged 62-75 years). In this randomised double blind cross over design study, we compared performance at baseline and again $2 \mathrm{~h}$ later after drinking one of the cocoa drinks, on two separate study days, separated by a 5-week washout. At each time point, participants completed sixteen cognitive tasks covering a broad range of cognitive functions including tests of executive function, which measures the ability to control, plan and regulate behaviour. Findings revealed a significant improvement in various aspects of executive function at $2 \mathrm{~h}$ following consumption of the HF drink compared with the LF one. Specifically, updating ability was improved, as measured using a letter memory task $(P=0.05)$ and the ability to inhibit responses was enhanced as shown by a reduction in response times in the Stroop $(P=0.03)$ and GoNogo $(P=0.01)$ tasks. These effects were accompanied by a reduction in diastolic blood pressure $(P=0.002)$ and an attenuation in the rise of stress related systolic blood pressure $(P=0.01)$.

\begin{tabular}{|c|c|c|c|c|}
\hline & \multicolumn{2}{|l|}{$(\mathrm{HF})$ cocoa } & \multicolumn{2}{|l|}{ (LF) cocoa } \\
\hline & Mean (change from baseline) & SE & Mean (change from baseline) & $\mathrm{SE}$ \\
\hline GoNogo (response time) & $-4.4 \mathrm{~ms}$ & 6.4 & $17.2 \mathrm{~ms}$ & 11.5 \\
\hline Stroop (response time) & $-23 \mathrm{~ms}$ & 7.0 & $-2.8 \mathrm{~ms}$ & 9.3 \\
\hline Letter memory & 1.76 correct responses & 0.8 & -0.38 correct responses & 0.88 \\
\hline Systolic BP & $0.3 \mathrm{mmHg}$ & 1.5 & $5.5 \mathrm{mmHg}$ & 1.6 \\
\hline Diastolic BP & $-2.5 \mathrm{mmHg}$ & 0.7 & $0.8 \mathrm{mmHg}$ & 0.8 \\
\hline
\end{tabular}

There were no significant improvements in other domains of cognitive function. In addition, and as expected, we found a highly significant difference $(P=<0.000)$ in the concentration of circulating flavanol metabolites $2 \mathrm{~h}$ after HF cocoa. Our findings suggest that cocoa flavanols may have a role to play in alleviating the symptoms of cognitive decline experienced in healthy ageing and in neurodegenerative diseases such as Alzheimer's where there are significant deficits in executive function.

1. Commenges D, Scotet V, Renaud S et al. (2000) Eur J Epidemiol 16, 357-363.

2. Sorond FA, Lipsitz LA, Hollenberg NK et al. (2008) Neuropsychiatr Dis Treat 4, 433-440.

3. Grassi D, Necozione S, Lippi C et al. (2005) Hypertension 46, 398-405.

4. Scholey AB, French SJ, Morris PJ et al. J Psychopharmacol 24, 1505-1514. 